\title{
Retraction Note: Sirtuin 3 inhibition induces mitochondrial stress in tongue cancer by targeting mitochondrial fission and the JNK-Fis 1 biological axis
}

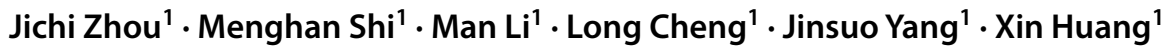

Accepted: 12 July 2021 / Published online: 25 August 2021

(c) Cell Stress Society International 2021

\section{Retraction Note to: Cell Stress and Chaperones (2019) 24:369-383 \\ https://doi.org/10.1007/s12192-019-00970-8}

The Editor-in-Chief has retracted this article (Zhou et al. 2019) because of significant overlap was detected with text and figures in articles submitted and published within a close time frame. Specifically, there is text overlap with an article by different authors (Wei et al. 2019) published earlier. There is also text overlap and similarity between Fig. 3c 'si2-Sirt3' and Fig. 3a 'Ad-Mst1' in an article by unrelated authors (Ouyang et al. 2019) that was submitted before this article.

The authors did not respond to any correspondence from the editor or publisher about this retraction.

\section{References}

Zhou J, Shi M, Li M et al (2019) Sirtuin 3 inhibition induces mitochondrial stress in tongue cancer by targeting mitochondrial fission and the JNK-Fis1 biological axis. Cell Stress Chaperones 24:369-383. https://doi.org/10.1007/s12192-019-00970-8

The original article can be found online at https://doi.org/10.1007/ s12192-019-00970-8.

Xin Huang

huangyue874@sohu.com

1 Department of Oral and Maxillofacial Surgery, Beijing

Stomatological Hospital, Capital Medical University,

Tiantanxili 4, Dongcheng District, Beijing 100050, China
Wei B, Wang M, Hao W et al (2019) Mst1 facilitates hyperglycemiainduced retinal pigmented epithelial cell apoptosis by evoking mitochondrial stress and activating the Smad2 signaling pathway. Cell Stress Chaperones 24:259-272. https://doi.org/10.1007/ s12192-018-00963-Z

Ouyang H, Zhou E, Wang H (2019) Mst1-Hippo pathway triggers breast cancer apoptosis via inducing mitochondrial fragmentation in a manner dependent on JNK-Drp1 axis. Onco Targets Ther 12:1147-1159. https://doi.org/10.2147/OTT.S193787

Publisher's note Springer Nature remains neutral with regard to jurisdictional claims in published maps and institutional affiliations. 